\title{
VALIDATION OF NUMERICAL SIMULATION USING 3D-DISCRETE ELEMENT BALLASTED TRACK MODEL
}

\author{
AKIKO KONO \\ Railway Technical Research Institute, Japan
}

\begin{abstract}
The Discrete Element Method (DEM) is extensively used not only in geomechanics but also in railway engineering to model ballasted tracks. DEM can simulate peculiar deformation characteristics of ballasted layer, for examples, differential settlements around rail joints and migrations of ballast grains around canted track. DEM enable us to observe the micromechanical process of formation of such settlements or migrations. However, the quantitative accuracy of DEM has not been examined in railway engineering field. Then the author carried out a series of simple box tests by applying cyclic sinusoidal loadings on ballasted layers with same thickness and grading of real ballasted track. The series of tests have two cases of stiffness of box base, with and without rubber mat. The author took images of the ballast layers by using a high-speed camera to observe the behaviour of ballast grains with micromechanical views. Then the figures were analysed by using Particle Imaging Velocimetry to visualize the movement of ballast grains. At the same time, the author simulates the simple box test by DEM to validate the discrete element model of ballasted layer. The DEM results show that the difference of amplitude of loading plate's displacement is influenced by contact stiffness of ballast grains predominantly, and that the difference of ballast settlement is influenced by friction coefficient between ballast grains predominantly.
\end{abstract}

Keywords: ballasted layer, cyclic loading test, discrete element model, validation.

\section{INTRODUCTION}

The Discrete Element Method (DEM) is extensively used in railway engineering to model ballasted tracks [1], [2]. DEM can simulate peculiar deformation characteristics of ballasted layer, for examples, differential settlements around rail joints and migrations of ballast grains around canted track. DEM enable us to observe the micromechanical process of formation of such settlements or migrations. However the quantitative accuracy of DEM has not been examined in railway engineering field.

The author carried out a series of simple box tests by applying cyclic sinusoidal loadings on ballasted layers with same thickness and grading of real ballasted track. At the same time, the author simulates the simple box test by DEM to validate the discrete element model of ballasted layer.

Then the author evaluates the influence of DEM parameter for quantitative accuracy of the model by comparing numerical and experimental test result.

\section{CYCLIC LOADING TEST ON THE BALLASTED LAYER IN A STEEL BOX}

\subsection{Summary of the test}

\subsubsection{The ballasted layer}

Fig. 1 shows that the steel box $1000 \mathrm{~mm}$ wide and $300 \mathrm{~mm}$ deep contains a ballasted layer of $250 \mathrm{~mm}$ thickness, which is the same value at the real railway ballasted rail. The ballasted layer is composed of new andesite ballast stones.

Fig. 2 shows the standard range of grain size distributions of fresh ballast grains in Japan. 
The ballasted layer model is constructed by deposing three layers of one third of the total thickness, each of which is compacted by a vibrator. The bulk density of the ballasted layer model was $1.54 \mathrm{~g} / \mathrm{cm}^{3}$, although that of real ballast layers compacted enough is known to be about $1.67 \mathrm{~g} / \mathrm{sm}^{3}$ from previous studies [3]. For this reason, it is supposed that the void between the side faces and ballast grains tends to be large.

\subsubsection{The case regarding steel box base conditions}

There were two cases regarding the box base conditions; one is the case without the rubber mat and the other is the case with it as shown in Fig. 3(a). The rubber mat is used for the base mat of the ballasted track on viaducts and generally has $20 \mathrm{~mm}$ thickness and a spring coefficient of $4 \mathrm{MN} / \mathrm{m}$.

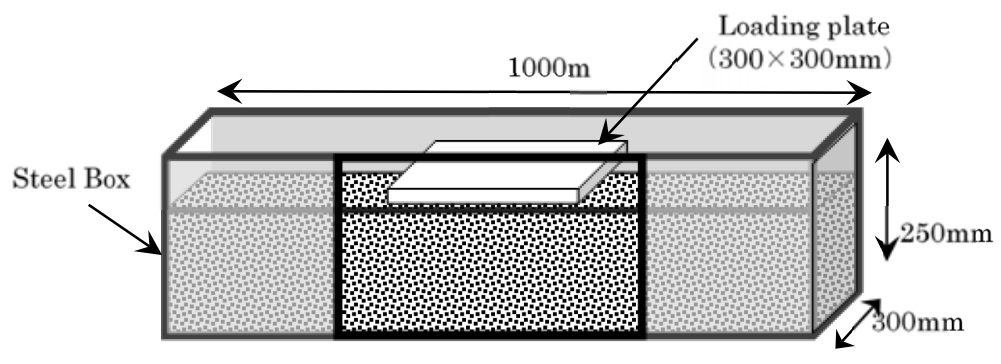

Figure 1: Size of the ballasted layer in the box.

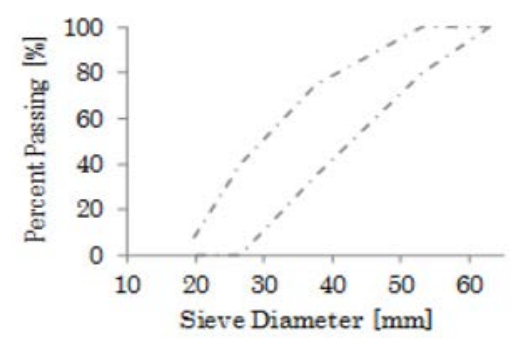

Figure 2: Grain size distribution of ballast grains in Japan.

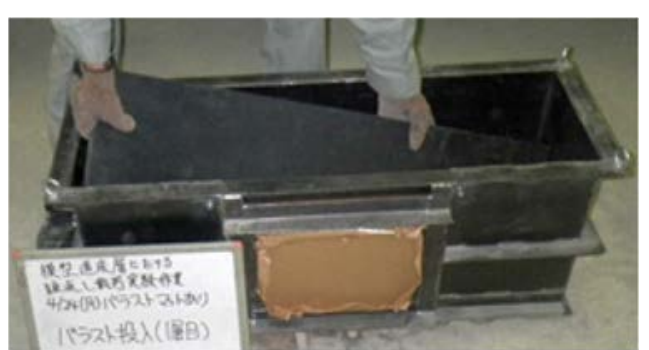

(a)

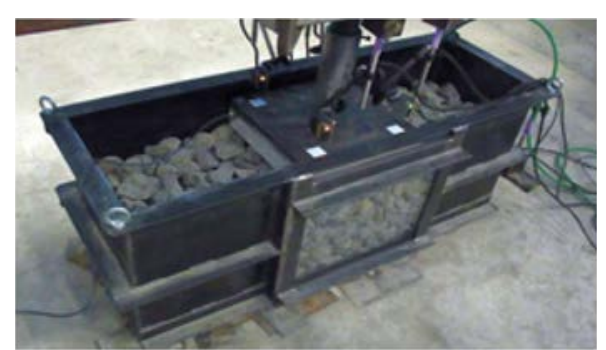

(b)

Figure 3: Setup of ballasted layer in the steel box. (a) Rubber mat; (b) Cyclic loadings test. 


\subsubsection{Loading conditions}

The loading plate $300 \mathrm{~mm}$ square is used for cyclic loadings. The plate has a cover steel plate, a bottom concrete block and piezo electric load sensors between the plate and block.

The displacement of the loading plate is measured by four razor displacement sensors.

The load is applied in the range from $1 \mathrm{kN}$ to $20 \mathrm{kN}$ at a frequency of $7 \mathrm{~Hz}$. The cyclic loading is paused after repeating 100 times, and then restarts to repeat another 900 times.

\subsection{Test results}

\subsubsection{The displacement of the loading plate}

Fig. 4 shows a part of the displacement waveform of the loading plate. This wave shows the average value of the data measured by 4 razor sensors. The figure shows that the displacement by the 1st loading is remarkable, which is caused by the contact between plane steel face contacts the uneven ballasted layer composed of coarse grains.

The wave forms contain periodic displacement caused by the elastic deformation of the ballasted layer and the accumulation of the displacement caused by the plastic deformation of ballasted layer. The former one is expressed as "displacement amplitude" and the latter one is expressed as "settlement" in this paper.

Fig. 5 shows the displacement waveform during all the cyclic loading process. Fig. 5(a) shows the result of the case without the rubber mat and Fig. 5(b) shows that with the rubber mat.

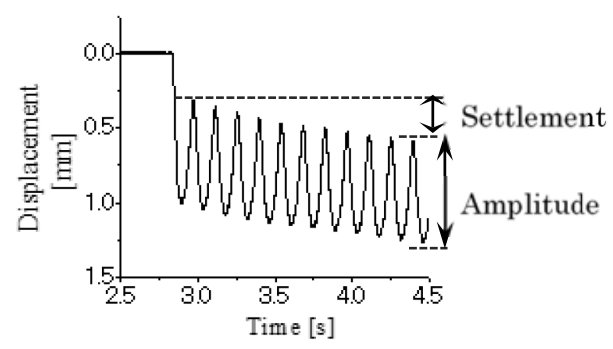

Figure 4: A part of displacement wave of loading plate measured by laser displacement sensors.

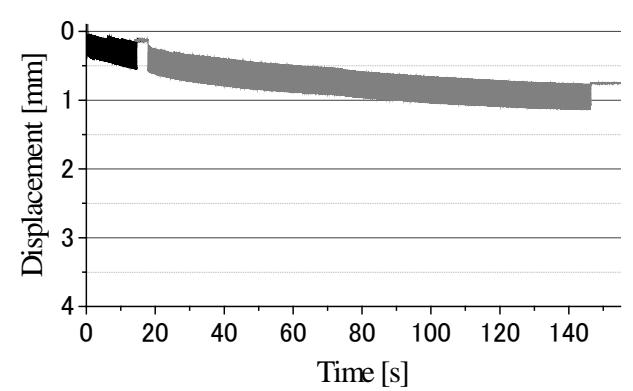

(a)

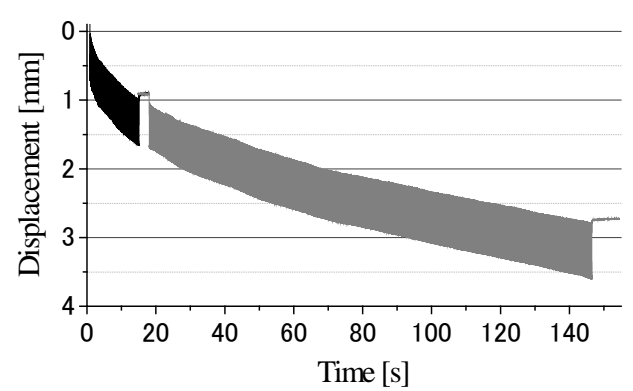

(b)

Figure 5: The waveforms of vertical displacement of loading plate. (a) Without rubber mat; (b) With rubber mat. 
The figure shows that the displacement amplitude in the case without rubber mat is 0.38 $0.4 \mathrm{~mm}$, and that with the rubber mat is $0.7-0.8 \mathrm{~mm}$.

The settlements are derived from the difference between the maximum displacement at the 101st loading and that at the 1000th loading as shown in the figures. These shows that the settlement in the case without the rubber mat is $0.6 \mathrm{~mm}$, and that with the rubber mat is $1.9 \mathrm{~mm}$.

These results show a tendency similar to the phenomena observed in the real railway lines in that the settlement of ballasted layer increase when it is on the subgrade with lower stiffness [4].

\subsubsection{The deformation of ballast layer}

The vertical displacement of the loading plate shown in Fig. 5 seem to include deformation of rubber mat itself. Then Fig. 6 shows an example of images of ballasted layer taken by high speed camera during cyclic loading test to observe the deformation of ballasted layer.

Fig. 7 shows the results after the image process by using Particle Imaging Velocimetry (PIV) [5]. This figure shows the contour and vectors of displacement of each grid point in the image during load increasing process at the 100th loading. The colour scale indicates the distance of each grid point in the original images during the process. The arrays express the distance and direction of each grid point from the original images. The start point of each array shows the position of image point at the minimum loadings and the end point of that shows that at the maximum loadings at the 100th loading.

The average value of the displacement of upper layer is around $0.5 \mathrm{~mm}$ and that of bottom layer is around $0.2 \mathrm{~mm}$ or less at the case without rubber mat. The average value of the

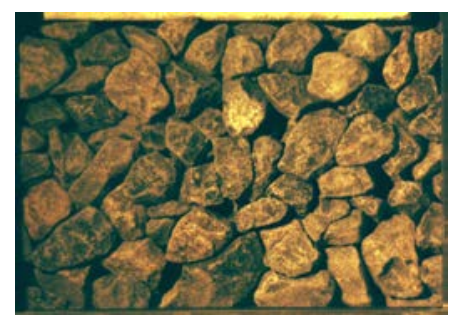

Figure 6: An example of image of ballasted layer taken by high speed camera.

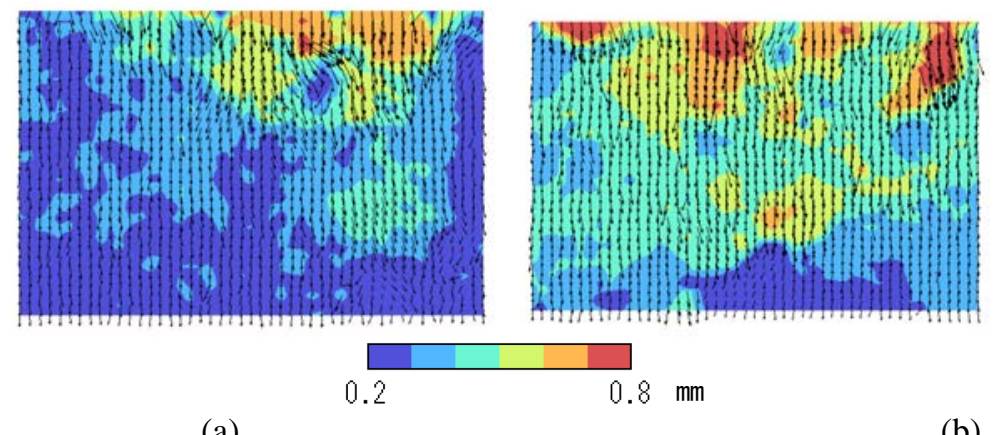

Figure 7: The contour and the vectors of displacement of the grid points. (a) Without rubber mat; (b) With rubber mat. 
displacement of upper layer is around $0.8 \mathrm{~mm}$ and that of bottom layer is around 0.35 at the case with rubber mat.

These results express that the deformation of ballast layer to the thickness direction is around $0.3 \mathrm{~mm}$ at the case without rubber mat and is around 0.45 at the case with it. It suggests that the difference of the deformation of ballast layer itself is just only $0.15 \mathrm{~mm}$ comparing two case with/without rubber mat although the difference of the residual settlement of them is $3 \mathrm{~mm}$ or less after 1000 cycles loadings.

\section{SIMULATION OF CYCLIC LOADING TEST BY USING DEM}

RTRI has developed a series of discrete ballasted track models with various boundary conditions and has carried out a series of discrete element method (DEM) simulations under various external loading conditions. These discrete models have discrete ballast elements composed of clumped-spheres with irregular shapes similar to those of actual ballast grains. These models enable observation of the distribution of inter-particle contact force and the individual behaviour of ballast grains in ballasted layers which are difficult to measure by using existing sensors.

In this paper, the author made a model of the ballast layer with same scale of that at the box test mentioned in Section 2.

\subsection{Summary of the simulation}

\subsubsection{Discrete element model of ballast grains}

The ballast grains are modelled by clumped-spheres elements composed of solid spheres with various diameters, herein after "CS-ballast" as shown in Fig. 8(a). The irregular shapes of ballast elements are created by "Dynamic Optimization" [6] using scanned data of the 3D shape of actual ballast grains as shown in Fig. 8(b).

\subsubsection{Modelling of the ballasted layer in steel box}

Fig. 8(c) shows the ballasted layer model composed of the ballast grain element mentioned above. The gradation of ballast elements of this model accurately follows the standard for actual ballast grains as shown in Fig. 2 . The bulk density of the model was $1.53 \mathrm{~g} / \mathrm{cm}^{3}$, the similar value of the ballast layer at the test mentioned in Section 2.

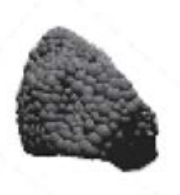

(a)

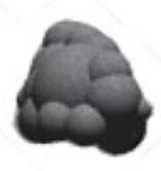

(b)

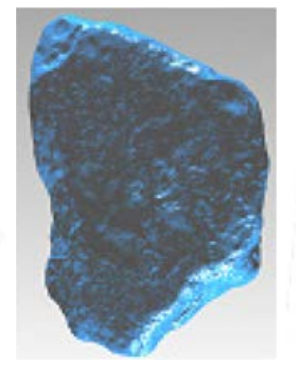

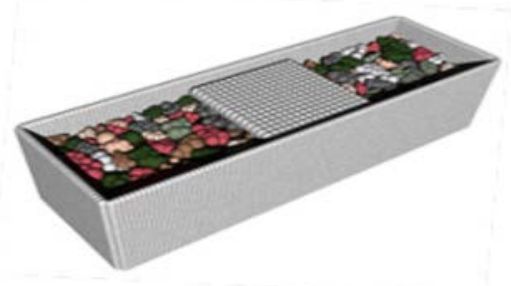

(c)

Figure 8: Modelling of ballast grains and ballasted layer. (a) Examples of "CS-ballast”; (b) An example of; (c) Discrete ballasted layer model image of 3D-scanning. 


\subsubsection{DEM parameters}

Table1 shows the DEM parameters in this study.

In DEM model, there are normal and tangential springs, normal and tangential dampers and sliders at the all contact point as shown in Fig. 9. So, we need to set these parameters as shown in Table 1.

The values of the normal and tangential spring constants at Case 1 were determined from the measured velocities of the compressive and shear waves in a previous study [7]. For the parametric study, spring constants at Case 2 is 10 times of the Case 1 and that at Case 3 is 1 to 10 of the Case 1 .

The normal and tangential damping coefficients, $C_{N}$ and $C_{S}$ are computed from the following equations:

$$
\begin{gathered}
e_{b}=\exp \left(-\frac{h \pi}{\sqrt{1-h^{2}}}\right), \\
h=\frac{C_{N}}{2 \sqrt{K_{N} m}}=\frac{C_{S}}{2 \sqrt{K_{S} m}},
\end{gathered}
$$

where $e_{b}$ is the restitution coefficient of the ballast grain, which is experimentally obtained as $e_{b}=0.2[8]$ and $h$ is the damping constant.

\begin{tabular}{|c|c|c|c|c|c|c|c|c|c|c|}
\hline & \multicolumn{5}{|c|}{ Ballast Grains } & \multirow{3}{*}{$\begin{array}{l}\text { Loading } \\
\text { plate }\end{array}$} & \multicolumn{2}{|c|}{ Box Base } \\
\hline & & & \multicolumn{3}{|c|}{ Case1 } & \multirow{2}{*}{ Case2 } & \multirow{2}{*}{ Case3 } & & \multirow{2}{*}{$\begin{array}{l}\text { without the } \\
\text { rubber mat }\end{array}$} & \multirow{2}{*}{$\begin{array}{l}\text { with the } \\
\text { rubber ma }\end{array}$} \\
\hline & & & $\mathrm{i}$ & ii & iii & & & & & \\
\hline Spring & normal & $K_{n}$ & \multicolumn{3}{|c|}{$6.88 \times 10^{6}$} & $6.88 \times 10^{7}$ & $6.88 \times 10^{5}$ & $8.0 \times 10^{6}$ & $4.0 \times 10^{6}$ & $4.0 \times 10^{6}$ \\
\hline$(\mathrm{N} / \mathrm{m})$ & tangential & $K_{s}$ & \multicolumn{3}{|c|}{$1.72 \times 10^{6}$} & $1.72 \times 10^{7}$ & $1.72 \times 10^{5}$ & $3.4 \times 10^{6}$ & $1.6 \times 10^{6}$ & $1.6 \times 10^{6}$ \\
\hline Damping & normal & $C_{n}$ & \multicolumn{3}{|c|}{375} & 1185 & 118.5 & 1005 & 471 & 471 \\
\hline$(\mathrm{N} \cdot \mathrm{s} / \mathrm{m})$ & tangential & $C_{s}$ & \multicolumn{3}{|c|}{187.5} & 592.5 & 59.25 & 657 & 298 & 298 \\
\hline \multicolumn{2}{|c|}{ Friction Coff. (degree) } & $\mu$ & 20 & 36 & 45 & 36 & 36 & 20 & 20 & 20 \\
\hline
\end{tabular}

Table 1: DEM parameters.

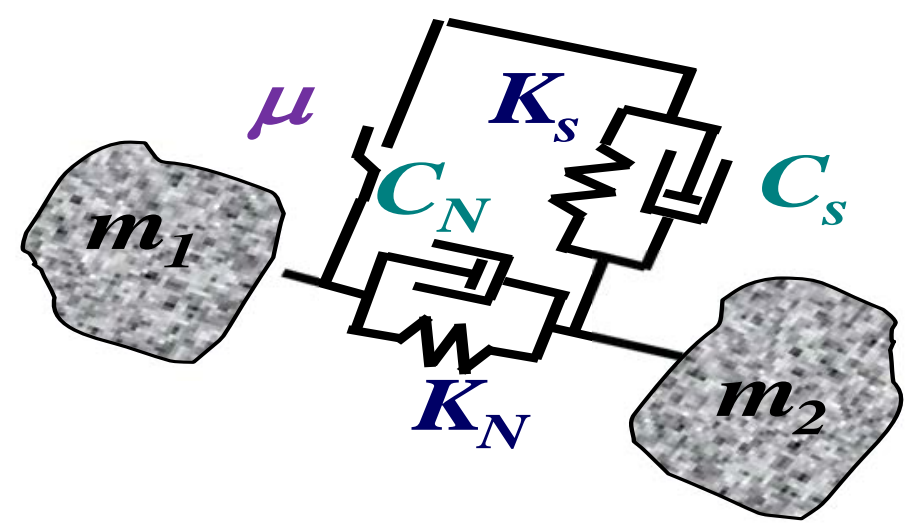

Figure 9: Parameters in DEM. 
The value of the intergranular friction coefficients, 36 degree and 45 degree are obtained from previous study [9]. The friction coefficient of 20 degree was set to evaluate the effect of the coefficient on the settlement of ballasted layer in DEM simulations.

\subsubsection{Loading conditions}

The cyclic loadings are applied to the loading plate element in DEM mode as shown in Fig. 8 (c). The load range is from $1 \mathrm{kN}$ to $20 \mathrm{kN}$, the same value at the test. However, the lading frequency is $8 \mathrm{~Hz}$ at the DEM simulation to prevent the time step being repeating decimal.

\subsection{Results from DEM simulation}

\subsubsection{The effect of spring constants}

Fig. 10 shows the displacement waveform during the first 50 cycles' loadings process from DEM simulation at the three cases with different spring constants as shown in Table 1.

The figure shows that the displacement amplitude during 50 cycles' loadings is around $0.4 \mathrm{~mm}$ at Case $1,0.17 \mathrm{~mm}$ at Case 2 and $2.5 \mathrm{~mm}$ at Case 3. The figure shows that the settlements after 50 cycles' loadings is $0.28 \mathrm{~mm}$ at Case $1,0.24 \mathrm{~mm}$ at Case 2 and $0.37 \mathrm{~mm}$ at Case3.

These results express that spring constants in DEM don't effect on the settlement of the ballast layer but on the amplitude clearly.

\subsubsection{The effect of friction coefficient}

The Fig. 11 shows the displacement waveform during 100 cycles loading process from DEM simulation at the three cases with different friction coefficient as shown in Table 1. Fig. 11(a) and 11(b) shows the result at the case without the rubber mat and that at the case with the mat respectively.

Fig. 11(a) shows that the displacement amplitude during 100 cycle's loadings is around $0.45 \mathrm{~mm}$ at the Case1-i, $0.44 \mathrm{~m}$ at the Case1-ii and $0.4 \mathrm{~mm}$ at the Case1-iii. The figure shows that the settlements after 100 cycle loadings is $5.96 \mathrm{~mm}$ at the Case1-i, $0.38 \mathrm{~mm}$ at the Case1ii and $0.23 \mathrm{~mm}$ at the Case1-iii with the largest friction coefficient.

Fig. 11(b) shows that the displacement amplitude during 100 cycle's loadings is around $0.9 \mathrm{~mm}$ at the Case1-i, $0.65 \mathrm{~m}$ at the Case1-ii and $0.65 \mathrm{~mm}$ at the Case1-iii. The figure shows that the settlements after 100 cycle loadings is $8.13 \mathrm{~mm}$ at the Case1-i, $0.9 \mathrm{~mm}$ at the Case1ii and $0.3 \mathrm{~mm}$ at the Case1-iii.

These results express that friction coefficients in DEM don't effect on the amplitude but on the settlement clearly.

\subsubsection{The effect of friction coefficient}

Table 2 shows the values of displacement amplitude and settlement from the series of DEM simulation and experiment during 100 cycle loadings. It shows that the displacement of ballasted layer from DEM show similar values at the Case1-ii, -iii, with 36-45 degrees of friction coefficient. 


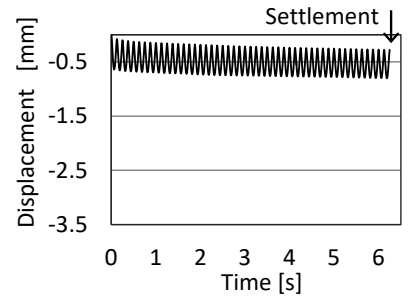

(a)

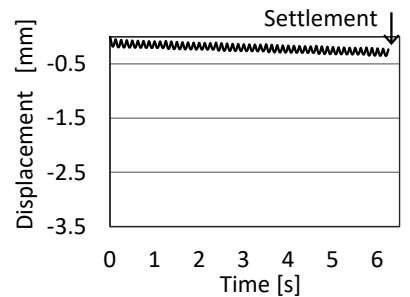

(b)

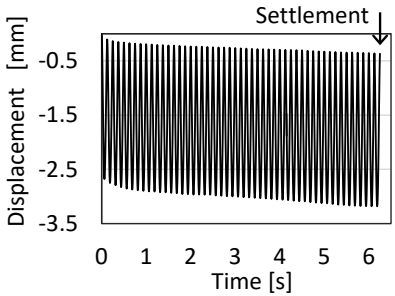

(c)

Figure 10: Waveform of vertical displacement from DEM simulation. (a) Case 1 $\mathrm{K}=$ Standard; (b) Case $2 \mathrm{~K}=\mathrm{x} 10$ (c) Case $3 \mathrm{~K}=1 / 10$.

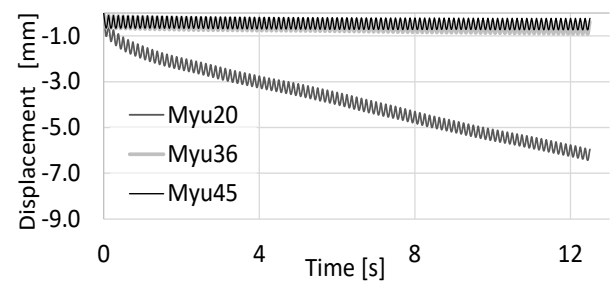

(a)

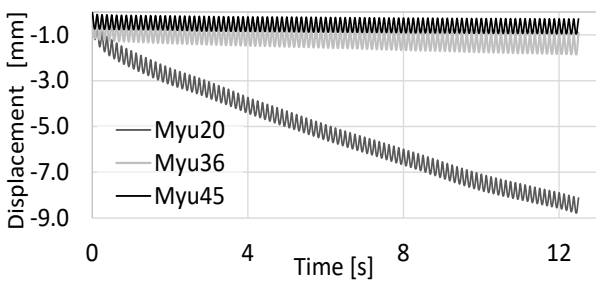

(b)

Figure 11: Waveform of vertical displacement from DEM simulation. (a) Without rubber mat; (b) With rubber mat.

Table 2: The results from experimental and numerical test.

\begin{tabular}{|c|r|c|c|c|c|}
\cline { 3 - 6 } \multicolumn{2}{c|}{} & \multirow{2}{*}{ Expriment } & \multicolumn{3}{|c|}{ Simulation } \\
\cline { 3 - 6 } \multicolumn{2}{c|}{} & & $\begin{array}{c}\text { Case1-i } \\
\text { Myu20 }\end{array}$ & $\begin{array}{c}\text { Case1-ii } \\
\text { Myu36 }\end{array}$ & $\begin{array}{c}\text { Case1-iii } \\
\text { Myu45 }\end{array}$ \\
\hline \multirow{2}{*}{$\begin{array}{c}\text { Without } \\
\text { the mat }\end{array}$} & Amplitude[mm] & 0.4 & 0.45 & 0.44 & 0.4 \\
\cline { 2 - 6 } & Settlements[mm] & 0.2 & 5.96 & 0.38 & 0.23 \\
\hline \multirow{2}{*}{$\begin{array}{c}\text { With } \\
\text { the mat }\end{array}$} & Amplitude[mm] & 0.75 & 0.9 & 0.65 & 0.65 \\
\cline { 2 - 6 } & Settlements[mm] & 0.9 & 8.13 & 0.9 & 0.3 \\
\hline
\end{tabular}

\section{CONCLUSION}

The author carried out a series of cyclic loadings test on ballasted layers experimentally and numerically. These results show that the DEM enable to simulate the ballast settlement qualitatively. Furthermore, these results show that the results from DEM shows that the spring constants derived from elastic wave of ballasted layer is reasonable comparing the displacement amplitude from experimental test and that the 36-45 of friction coefficient is reasonable comparing the settlement of the ballast layer from experimental test, quantitatively. 


\section{REFERENCES}

[1] Saussine, G. et al., Modeling ballast behavior under cyclic loading using discrete element method. Proceedings of "Cyclic Behavior of Soils and Liquefaction Phenomena”, Balkema, pp. 649-658, 2004.

[2] Ferellec, J.F. \& McDowell, G.R., Innovative sleeper design analysis using DEM. Advance in Transportation Geotechnics, pp. 692-697, 2012.

[3] Sunaga, M. \& Enomoto, H., Density measurement of rail ballast by using radioisotope. RTRI Report, 6(10), pp. 47-54, 1992.

[4] Senda, K. et al., Influence of roadbed and ballast vibration on track settlement in highspeed railway. Proceedings of Railway Engineering 2017, CD-ROM, 2017.

[5] Saomoto, H. et al., Development of LAT-PIV visualization technique for particle-fluid system. Journal of Structural Engineering, 24, pp. 123-130, 2007.

[6] Matsushima, T. \& Saomoto, H., Discrete element modelling for irregularly-shaped sand grains. Proceedings of NUMGE2002: Numerical Methods in Geotechnical Engineering, pp. 239-246, 2002.

[7] Minaki, T. et al., A study on estimation of stiffness for ballast roadbed using P-S layer inspection method. Journal of Pavement Engineering, JSCE, 6(6), pp. 132-137, 2001.

[8] Nakashima, Y. et al., Influence of kinetic energy and posture on rock collision behaviour. Proceedings of Symposium on Structural Impact Problems, JSCE, 7, pp. 139-142, 2004.

[9] Kono, A. \& Matsushima, T., 3D-DEM simulation about dynamic behaviours of ballasted track under impact loading. Proceedings of Railway Engineering 2011, CDROM, 2011. 